\title{
A STUDY ON HEALTH SEEKING BEHAVIOR OF PATIENTS WITH GENITAL ULCER DISEASE
}

Meetesh Agrawal ${ }^{1}$, Swarupa Chakole ${ }^{2}$

\section{HOW TO CITE THIS ARTICLE:}

Meetesh Agrawal, Swarupa Chakole. "A Study on Health Seeking Behavior of Patients with Genital Ulcer Disease". Journal of Evolution of Medical and Dental Sciences 2014; Vol. 3, Issue 10, March10; Page: 2614-2619, DOI: $10.14260 /$ jemds/2014/2182

BACKGROUND: In developing countries, the proportion with STDs who present with genital ulcers is high compared to developed nations. AIM: 1 . To study reaction of the cases toward their disease. 2 . To study communication of cases with their partners. 3. To study treatment of symptoms and starting treatment, selfmedication \& completion of treatment. 4. To study approach of health care providers. STUDY SETTINGS: Present study was carried out in Department of skin and VD, Medical College and SSG Hospital Baroda between June 2001 to Feb. 2003. MATERIAL AND METHODS: A cross sectional study was conducted. Sexually active male or female having genital ulcer with history of exposure in patient or partner. Total 216 cases were included in the study. Detailed history was taken and was recorded. An attempt was made to study health care seeking behavior in 60 cases. These cases were questioned about their reaction towards the disease treatment seeking including completion of treatment and time gap between appearance of symptoms and treatment taken were asked. They were also asked about the approach of the health care providers from whom they took treatment before coming to our clinic. RESULTS: It was observed that $57 \%$ of the cases among males were frightened after having GUD. They were likely to come to STD clinics at the earliest for treatment. Spousal communication was only $45 \%$ in male cases. Only $1 / 3^{\text {rd }}$ cases came directly to STD clinic and the other visited other practitioners. Among these, only $60 \%$ took treatment from MBBS doctors or STD specialist. Rest of them went to unqualified health. Awareness about protective value of condom, as for as STI prevention is concerned, was $70 \%$ but consistent use was seen only in $2 \%$ cases. Twenty one percent cases did not know how to use condom, and 7\% did not know about condoms at all. As many as $89 \%$ cases didn't feel it necessary to use condoms during sexual relations with wife. CONCLUSION: Creating awareness promoting safe sex method including female driven devices, training doctors and other paramedical workers along with help of outreach workers may be appropriate strategies to combat STIs in future.

KEYWORDS: Genital ulcer disease

INTRODUCTION: Sexually Transmitted Diseases (STDs) pose a public health problem of major significance in most parts of the world and South-East Asia was no exception. ${ }^{1}$ The presence of high prevalence of asymptomatic disease is a barrier to effective control. ${ }^{2}$ Even when symptoms occur, their presentation can overlap with and be diagnosed as a normal physiological change and normal physiological discharge may be misdiagnosed as RTI's. ${ }^{3}$ In some instances, despite availability of best services, symptomatic persons do not seek or delay in seeking appropriate diagnostic and treatment services. ${ }^{4}$ RTI's entail a heavy toll on women, if untreated can cause serious consequences of infertility, ectopic pregnancy, cervical cancer, menstrual disturbances, pregnancy wastage and low birth weight babies. 
Genital ulcer syndrome is a frequent presentation of sexually transmitted disease, especially in developing countries, like ours. There are number of different causes of genitor ulcer disease, and since the clinical presentation of each may be variable and the treatment for each different, genital ulcer syndrome creates considerable and management problem for clinicians.

In developing countries, the proportion with STDs who present with genital ulcers is high compared to developed nations. Herpes progenitalis is the most common cause of genital ulcer in developed and most parts of developing world. The genital ulcer disease or genital ulcer syndrome is defined as a breach of the epithelium of the genital skin or mucous membranes, usually by sexually acquired organisms resulting in the formation of lesions. During the course of the disease the inguinal and/or femoral lymph nodes may be enlarged resulting in a combination of ulceration and lymphadenopathy for be appropriate. While we recognize the importance of intervention programs providing preventive measures, we also realize that a certain percentage of the population is already infected. Obviously, for a meaningful intervention aiming at prevention and control of STDs, the already infected population needs some sort of psychological, social and medical attention, which necessitates the planning and implementation of relevant intervention programs. In this regard, answers to the following questions become relevant. Are there adequate facilities and human resources to meet the psychological, social and medical needs of STD patients in this part of the world? Are the patients ready to make full use of the available resources? What is the nature of their health-seeking behavior?

\section{AIM AND OBJECTIVES:}

1. To study reaction of the cases toward their disease.

2. To study communication of cases with their partners.

3. To study treatment of symptoms and starting treatment, self-medication \& completion of treatment.

4. To study approach of health care providers.

\section{MATERIAL AND METHODS:}

Present study was carried out in Department of skin and VD, Medical College and SSG Hospital Baroda between June 2001 and Feb. 2003. Two hundred and sixteen cases having genital ulcers were included in the study.

INCLUSION CRITERIA: Sexually active male or female having genital ulcer with history of exposure in patient or partner.

Detailed history was taken and was recorded. Inquiries were made regarding age, educational status, occupation, marital status and details of their complaints.

An attempt was made to study health care seeking behavior in 60 cases. The cases were selected randomly and in depth interview was taken after their consent. The interview was carried out as per the structured Performa.

These cases were questioned about their reaction towards the disease treatment seeking including completion of treatment and time gap between appearance of symptoms and treatment taken were asked. They were also asked about the approach of the health care providers from whom they took treatment before coming to our clinic. 
All the data were recorded in a Proforma. It was tabulated analyzed and an attempt was made to compare data of present of study with other available studies.

An attempt was made to study the health care seeking behavior of 60 cases with GUD.

\section{RESULTS AND DISCUSSION:}

\begin{tabular}{|l|c|c|c|}
\hline \multicolumn{1}{|c|}{ Reaction } & $\begin{array}{c}\text { Male } \\
(\mathbf{n = 5 6 )}\end{array}$ & $\begin{array}{c}\text { Female } \\
(\mathbf{n = 4 )}\end{array}$ & $\begin{array}{c}\text { Total } \\
(\mathbf{n = 6 0 )}\end{array}$ \\
\hline Frightened (Required urgent treatment) & $32(57.1 \%)$ & $01(25 \%)$ & $33(55 \%)$ \\
\hline $\begin{array}{l}\text { Took as Non-serious problem } \\
\text { (Requiring treatment) }\end{array}$ & $18(32.1 \%)$ & $01(25 \%)$ & $19(31.7 \%)$ \\
\hline $\begin{array}{l}\text { Took as Non-serious problem } \\
\text { (Requiring no treatment) }\end{array}$ & $06(10.7 \%)$ & $02(50 \%)$ & $08(13.3 \%)$ \\
\hline \multicolumn{1}{|c|}{ Total } & $\mathbf{5 6 ( 1 0 0 \% )}$ & $\mathbf{0 4 ( 1 0 0 \% )}$ & $\mathbf{6 0 ( 1 0 0 \% )}$ \\
\hline \multicolumn{2}{|c|}{}
\end{tabular}

Table 1: Reaction of the cases

At least $57 \%$ of the males were frightened and were likely to go for treatment at the earliest.

Remaining $43 \%$ cases may not go for treatment at earlier stage and are prone to complication and sequel of STD. These cases are more likely to transmit STIs.

\begin{tabular}{|c|c|c|c|}
\hline Person & Married & Unmarried & Total \\
\hline Spouse & $18(45 \%)$ & - & $18(30 \%)$ \\
\hline Friend & $07(17.5 \%)$ & $12(60 \%)$ & $19(31.7 \%)$ \\
\hline Relative & $03(7.5 \%)$ & $06(30 \%)$ & $09(15 \%)$ \\
\hline Not communicated & $12(30 \%)$ & $02(10 \%)$ & $14(23.3 \%)$ \\
\hline Total & $\mathbf{4 0}(\mathbf{1 0 0} \%)$ & $\mathbf{2 0}(\mathbf{1 0 0} \%)$ & $\mathbf{6 0}(\mathbf{1 0 0 \% )}$ \\
\hline
\end{tabular}

Table 2: Person with whom communicated

Overall communication was more unmarried (90\%) compared to married (70\%) male cases.

$45 \%$ of the married male cases communicated with their spouses, $25 \%$ with friends and relatives and as 3\% didn't communicated at all.

Spousal communication is the first step towards not only safe sex promotion and condom use, but also for partner notification.

\begin{tabular}{|c|c|}
\hline Time gap & No. of cases \\
\hline Within 1 week & $42(70 \%)$ \\
\hline Within 2 week & $13(21.7 \%)$ \\
\hline Within 1 month & $03(5 \%)$ \\
\hline More than 1 month & $02(3.3 \%)$ \\
\hline Total & $\mathbf{6 0}(\mathbf{1 0 0} \%)$ \\
\hline
\end{tabular}

\section{Table 3: Time gap between appearance of}

symptoms and attending STD OPD 
Seventy percent of the cases came within one week for treatment but $30 \%$ took longer period. As highlighted, delay in STD treatment has lots of impact on STD cases, their partners and community.

\begin{tabular}{|c|c|}
\hline Pathway & No. of cases \\
\hline Cases coming directly to STD OPD & $20(33.3 \%)$ \\
\hline Actions taken before coming to STD OPD & \\
\hline$>$ Visited 1 practitioner & $34(56.7 \%)$ \\
\hline$>$ Visited 2 practitioner & $06(10 \%)$ \\
\hline$>$ Visited 3 practitioner or more & $00(0 \%)$ \\
\hline $\begin{array}{c}\text { Total } \\
\end{array}$ & $60(100 \%)$ \\
\hline
\end{tabular}

Only one -third cases directly came to STD OPD AND REST TOOK TREATMENT FROM ONE OR MORE PRACTITIONERS. These $2 / 3^{\text {rd }}$ cases might not have received proper treatment.

\begin{tabular}{|l|c|c|}
\hline \multicolumn{1}{|c|}{ Approach } & Yes & $\mathbf{\%}$ \\
\hline Asked History of exposure & 12 & $30 \%$ \\
\hline Discussed mode of transmission & 06 & $15 \%$ \\
\hline Examined affected parts & 13 & $32.5 \%$ \\
\hline Discussed safe sex measures/condom use & 05 & $12.5 \%$ \\
\hline Advise abstinence till complete cure & 04 & $10 \%$ \\
\hline Suggested partner management & 03 & $7.5 \%$ \\
\hline
\end{tabular}

Table 5: Approach of the health care providers ( $\mathrm{n}=40$ cases)

Approach of the health care providers was not according to the guidelines of STD management. Only $1 / 3^{\text {rd }}$ of the cases were examined and most of the cases were dealt with treatment based approach rather than comprehensive case management. Less than $10 \%$ of the cases were told about safe sex measures, condoms, abstinence till complete cure and only 7.55 were suggested partner management.

\begin{tabular}{|c|c|}
\hline \multicolumn{1}{|c|}{ Use of Condom } & No. of Cases (n=56) \\
\hline Purpose of using condom(n=44) & \\
$>$ Protection against pregnancy & $13(29.5 \%)$ \\
$>$ Protection against STDs & $05(11.4 \%)$ \\
$>$ Both & $26(59.0 \%)$ \\
\hline Frequency of using condom during EMR (n=52) & \\
$>$ Every time & $01(1.9 \%)$ \\
$>$ Some times & $09(17.3 \%)$ \\
$>$ Rarely & $05(9.6 \%)$ \\
$>$ Never & $37(71.2 \%)$ \\
\hline Reasons for not using condom with wife $(\mathrm{n}=36)$ & \\
$>$ Not available & $02(5.5 \%)$ \\
\hline
\end{tabular}




\begin{tabular}{|c|c|}
\hline$>$ Don't feel necessary & $32(88.9 \%)$ \\
$>$ Not available when needed & $02(5.5 \%)$ \\
\hline Don't know how to use condom & $12(21.4 \%)$ \\
\hline Don't know about condom & $04(7.14 \%)$ \\
\hline \multicolumn{2}{|c|}{ Table 6: Use of Condom } \\
\hline
\end{tabular}

$30 \%$ cases were considering condoms a device to protect against conception. Though seventy percent cases were aware that condom offer protection against STD, but only $2 \%$ cases were using it consistently and as high as $71 \%$ had never used condoms. Almost $89 \%$ of cases didn't feel it is necessary to use with wife.

$21 \%$ cases did not know how to use condoms and 7\% did not know about condom at all.

SUMMARY: It was an opportunity to observe the health care seeking behavior of GUD case during the course of the study.

It was observed that $57 \%$ of the cases among males were frightened after having GUD. They were likely to come to STD clinics at the earliest for treatment. Significant number of cases (43\%) took their problem lightly. Such cases were likely to come for treatment late or they might not come for treatment and hence were prone to complications.

Spousal communication was only $45 \%$ in male cases. This may be due to feeling of guilt, shame or the potential impact on married life. They were likely to transmit infection to their female partners and in turn to future generation.

Thirty percent of the cases look as long as 1 week to come to STD clinic after they had genital sores. This sort of treatment delay is undesirable not only for the cases themselves but also for their partners and the community.

Only $1 / 3^{\text {rd }}$ cases came directly to STD clinic and the other visited other practitioners. Among these, only $60 \%$ took treatment from MBBS doctors or STD specialist. Rest of them went to unqualified health care providers who were not well versed with the STD prevention and management.

Twenty one cases took treatment from MBBS doctors but were not cured fully. This may be due to incompetence of such doctors in handling STDs. out of 40 cases who took treatment from these practitioners, 24 cases completed the treatment and only 3 were fully cured. Thus cure rate was quite low.

Approach of these health care providers was not according to the guidelines of STD management. Most of the patients were dealt with treatment based approach. Two third of the cases were not examined at all and less than $10 \%$ cases were advised safe sex measures, abstinence till cure and partner management.

Awareness about protective value of condom, as for as STI prevention is concerned, was 70\% but consistent use was seen only in $2 \%$ cases. Twenty one percent cases did not know how to use condom, and 7\% did not know about condoms at all. As many as 89\% cases didn't feel it necessary to use condoms during sexual relations with wife.

CONCLUSION: As STIs are more related to behavior of the cases than anything else it was important to know health seeking behavior of the cases. 
As many as $40 \%$ cases took their lightly and reluctantly starting treatment late. Most of the cases were not communicating with their spouses and in these cases use of safe sex method, condom use and partner management are ought to be a problem. Many of the cases choose to go to unqualified health care providers who are not familiar with STD management. Even the qualified medical practitioner's used treatment based approach and followed the comprehensive guidelines of syndromic management of STDs.

STDs are a complex problem involving socio-economic, behavioral and gender issues, thus needing a comprehensive approach covering not only STD cases and their partners but also the individuals with high risk sexual behavior. A lot of efforts are required to control RTIs and STIs in the community. It is important to make people aware about STIs. Outreach workers who can identify people with high risk sexual behavior and bring them to STD clinics are an absolute necessity. Empowerment of females and promotion of female driven protective devices are required.

Creating awareness promoting safe sex method including female driven devices, training doctors and other paramedical workers along with help of outreach workers may be appropriate strategies to combat STIs in future.

\section{REFERENCES:}

1. WORLD HEALTH ORGANIZATION (2000): The World Health Report, Health Systems: Improving Performance.

2. Elias C: Reproductive tract infections: Global impact and priorities for women's reproductive health. In Reproductive Health Matters. Volume 1. Edited by Adrienne Germain, King K Holmes, Peter Piot, Judith Wasserheit. Plenum Press, New York, 1992;1993:111-112

3. Trollope-Kumar K: Symptoms of reproductive tract infection-not all they seem to be. Lancet 1999, 354(9192):1745-1746

4. Malta M, Bastos FI, Strathdee SA, Cunnigham SD, Pilotto JH, Kerrigan D: Knowledge, perceived stigma, and care seeking experiences for sexually transmitted infections: a qualitative study from the perspective of public clinic attendees in Rio de Janeiro, Brazil. BMC Public Health 2007, $7: 18$.

\section{AUTHORS:}

1. Meetesh Agrawal

2. Swarupa Chakole

\section{PARTICULARS OF CONTRIBUTORS:}

1. Associate Professor, Department of Dermatology, R.D. Gardi Medical College, Ujjain.

2. Associate Professor, Department of Community Medicine, R.D. Gardi Medical College, Ujjain.

\section{NAME ADDRESS EMAIL ID OF THE}

\section{CORRESPONDING AUTHOR:}

Dr. Meetesh Agrawal, Department of Dermatology, R. D. Gardi Medical College, Ujjain.

E-mail: drmeetesh@yahoo.co.in

Date of Submission: 11/01/2014. Date of Peer Review: 13/01/2014. Date of Acceptance: 28/01/2014. Date of Publishing: 07/03/2014. 